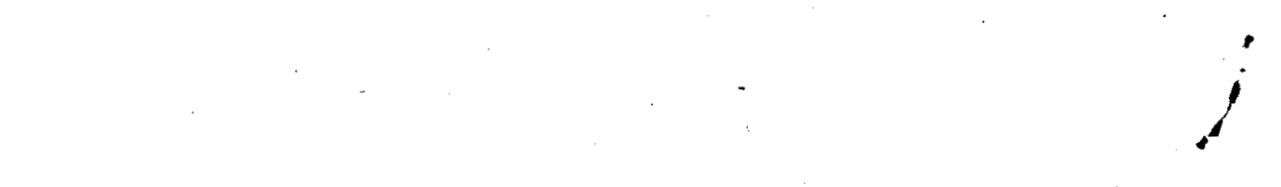

THEXTITES AS A GUDE TO THE STRUCTURE OF THE MOON

GPO PRICE

John A. O'Keefe

and

Paul D. Lowman, Jr.

\section{CFSTI PRICE(S) S}

Hard copy $(H C)$

Microfiche (MF)

$\frac{1.00}{.58}$

f 653 July 65

\begin{abstract}
TASA - Goddard Space Figint Center
Greenbelt, Maryland
\end{abstract}

Introduction

Although the moon has been studied telescopically for over 350 years, the amount which we can say with assurance about the chemical or physical.' structure of its surface is remarkably small. The shape of its vistble surface is known in more detail than Antarctica or the bottan of the sea; but the interpretation of the shape is almost always ambiguous. Either the craters are impact craters or they are volcanic; elther the maria are lava flows or they are deposits of fine particles, and so on.

What is clearly needed is a little hard information not subject to ambiguity. Some such indication can be obtained by compositional analysis, and several devices for chemical and mineralogical analysis are being
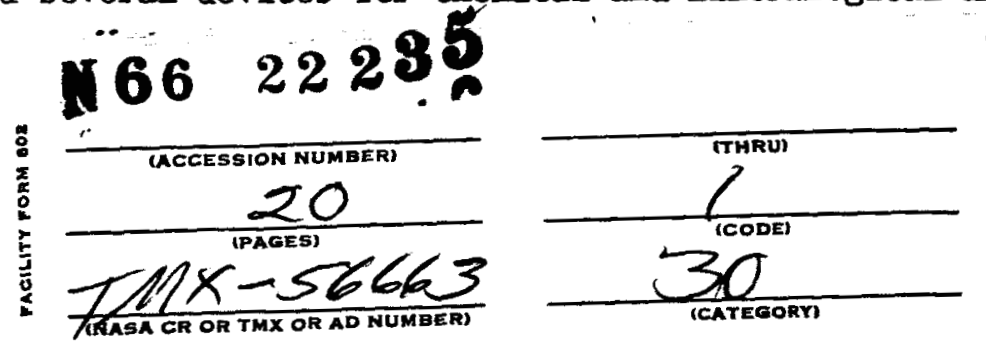
XERO 
considered for lunar probes in the immediate future. But perhaps the most useful piece of information would be a representative sample of the moon's surface. A prime aim of the contemplated landing of men on the moon will be to return carefully chosen samples.

It is a surprising fact, however, that such samples are almost certainly available on the surface of the earth, if we only knew how to locate them. The argument which leads to the conclusion is the following:

a. Typical meteorites move in space with a velocity of $17 \mathrm{~km} / \mathrm{sec}$, more or less (Whipple and Hughes, 1955).

b. The escape velocity from the moon is $2.3 \mathrm{~km} / \mathrm{sec}$.

c. The moon's atmosphere is approximately $10^{-13}$ of the earth's.

d. Laboratory studies (Charters, 1960) show that impact at meteorite velocities produces a sort of pseudo-explosion which will expel several thousand times the volume of the impacting body from a crater. Most of the expelled material moves at less than $2.3 \mathrm{~km} / \mathrm{sec}$, and hence would fall back to the moon, but a considerable amount ( 3 to 4 times the mass of the impacting meteorite in a representative case). would escape permanently from the moon and would go into orbit, either around the sun or around the earth (Gault, Heitowit and Moore, 1964).

Orbital calculations (Shute, 1962) have shown further that about half of the material thus expelled fram the moon will eventually fall on the earth, as a result of slow changes in the orbits of the earth and the particles. These changes in turn result from the attraction of the other 
planets (and, for the particles, from the attraction of the earth and moon).

Thus the problem of obtaining a sample of the surface of the moon can be considered as an intellectual problem: which of the rocks at the surface of the earth are from the moon?

In 2897, the Dutch mining engineer, Verbeek, proposed the idea that certain tektites were of extraterrestrial origin, since they seemed completely unconnected with the terrain in which they were found. He suggested that they were due to lunar volcanoes. In 1900, the great Austrian geologist F. E. Suess wrote a classic memoir supporting the extraterrestrial origin of tektites. He sympathized with Verbeek about the possible lunar origin, but was concerned about the velocity needed to escape the moon's gravity. In 1943, H. H. Nininger, an American meteoriticist, proposed that they result from meteorite impect on the moon. It is around this idea of Nininger's that the controversy has arisen, especially since 1958.

Whether lunar or not, tektites are in all probability the products of meteorite impact on some surface. In 1962, E. C. T. Chao and his co-workers rediscovered the tiny spherules of nickel-iron imbedded in same Philippine tektites which had earlier been mentioned very briefly by L. J. Spencer (1933). Later Chao found the same in some tektites from Indochina. The identification of the spherules as meteoritic was confirmed by the discovery of small crystals of an iron phosphide (schreibersite) and a sulfide (troilite) imbedded in the spherules. These two minerals are characteristic

$i$

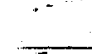


of meteorites; they are rarely or never found elsewhere; and in combination with the nickel-iron (kamacite) they render practically certain the identification of the spherules as meteoritic.

The significance of the spherules as indicators of impact is verified by the fact that entirely similar though much smaller spherules are found imbedded in material thrown out of terrestrial impact craters, especially those at Wabar in Arabia.

Very recently this diagnosis was confirmed by L. S. Walter at Goddard, who found coesite in a certain type of tektite. Coesite is a form of silica which is stable only when the pressure is above 16 kilobars. Up to the present it has been found in nature only in rocks from features which. are suspected on other grounds of resulting from the impact of giant meteorites, as at Barringer Crater, Arizona, the Ries Kessel, in Germany, and the Bosumtwi crater in Ghana.

As to the place where the impact took place, one can, it is generally agreed, rule out all celestial bodies more remote than the moon, for several reasons:

a. Tektites are found in large areas, extending hundreds or thousands of kilometers. These areas are called strewnfields, of which four are well established:

(1) The Far Eastern strewnfield, extending from South China to S. Australia. Tektites in this region were last melted some 700,000 years ago, as judged by potassium-argon dating. (The naturally occurring. isotope $\mathrm{K}^{40}$ decays into $\mathrm{A}^{40}$, which will escape if the rock is melted; hence measures of $K$ and $A^{40}$ give the age since last melting). 
This age agrees roughiy with the age of the rocks in which they are found, and is interpreted as the age when they fell.

(2) The Czechoslovakian strernfield is about $100 \mathrm{~km}$ in length by $35 \mathrm{~km}$ in breadth and fell some 15,000,000 years ago.

(3) The North American strewnfield is found where the uppermost Eocene is exposed in Massachusetts, Georgia and Texas; its total extent is unknown but probably enormous.

(4) The Ivory Coast strewnfield is generally considered to exist only near Ouellé, but recent discoveries have extended it as far as Oumé, at $5^{\circ} 30^{\prime} \mathrm{W}$; there is a possibility that a tektite has also been found in Nigeria.

Urey (1957) has pointed out that these strewnfields cannot be explained as resulting from the arrival of a huge swarm of tektites from interplanetary space. Such a swarm would have to have a density of at least one gram per cubic meter in order to resist the disruptive effects of the sun's attraction. But if it were several thousand kilometers in diameter, with this density, it would yield several million grams per square meter when it struck, which is far from the case:

Again, the distribution is too extended for a group of objects which arrived as one, but broke up in the atmosphere. In that case we get a strewnfield with a length of 10 kilometers, more or less, as is well known from theory and from several showers of meteorites, such as Puztusik or Holbrook (Mason, 1962). 
There remain two possibilities: earth impact with pieces strewn around the point of impact; or lunar impact. The latter could produce a strewnfield either by sending out a jet, like the jets which form the Iunar rays, or by sending out a single large chunk which happens to be trapped in orbit around the earth and is then broken up. Urey supports earth-impact, Chapman the jet, and we the single large chunk. These will be further discussed later on; for now we note that nobody sees how to account for the distribution if they arrive from interplanetary space somehow. A single chunk arriving from space is exceedingly unlikely to be trapped into a geocentric orbit; without this, distribution of the fragments seems impossible.

The same conclusion can be reached from another direction. A carefur search by Viste and Anders (1962) failed to show the radioactive 1sotopes $\mathrm{Be}^{10}$ and $\mathrm{Al}^{26}$, which are usually found in meteorites. They are produced by the attack of primary cosmic rays, which exist only outside the atmosphere. The upper limit to the amount of $\mathrm{Al}^{28}$ found is such that tektites cannot have existed in space as individual bodies more than about 100,000 years. They could have existed as a solid mass whose interior was protected against primary cosmic rays except that if such a mass were interplanetary there is no conceivable way by which it could be broken up and distributed over the strewnfields.

The tektites, terrestrial or lunar?

We conclude, therefore, that tektites result from impact either on the earth or on the moon. Up to this point all modern authorities agree. The great question is, now: earth or moon? 
In favor of origin from the earth are the following arguments: First, the localized distribution of tektites. If they come directly from the mocn as a narrow jet, following Chapman's theories (Chapman, 1964), then what happens to the jets which do not strike the earth? One would expect that this would be the case with the majority of tektites and that these jets would go into orbit, either around the earth or the sun. In either case, a large fraction should eventually fall to earth, after the swarm had been thoroughly broken up. Hence there should be a world-wide distribution of tektites. But it is reasonably sure, from the total lack of tektite discoveries in such well-searched localities as Fngland and Germany that there does not exist a unfform population of tektites but only a few discrete strewnfields. The single tektite found in Massachusetts turned out to belong to the same age and chemical grouping as the tektites of Georgia and Texas.

H. C. Urey and A. J. Cohen regard each of these strewnfields as resulting from a single meteorite impact on the earth. In particular, Cohen (1963) has suggested that the Czechoslovakian tektites (called moldavites) come from the Ries crater in Germany, and the Ivory Coast tektites from the Bosumtwi crater in Ghana. In both cases there is at least a rough agreement between the age of the crater and the age of the tektite, though further work on this point is urgently needed for the relation between Bosumtwi and the Ivory Coast tektites. 
This argument is not accepted by the other side, since there are no tektites found in or near the craters themselves, but only some hundreds of kilometers away. Moreover, a tektite sent over this distance would have to pass through a considerable thickness of air even if it followed a lobbing trajectory, up and then down. It turns out that no initial velocity is sufficient to propel a body of centimeter size upward through the undisturbed atmosphere. It will be stopped, regardless of its initial speed, when the mass of air which it has encountered becames equal to its own mass. Hence derivation of the Ivory Coast tektites from Bosumtwi is only possible if the explosion which formed the crater somehow removes the air. Calculations of blast waves show that a crater the size of Bosumtwi would not produce a blast wave sufficient to remove the atmosphere. However, Hawkins has suggested that the explosion will drive enough solid matter through the air to clear a path. This seems to be more reasonable; however, one must then ask why this presumably much more abundant mass is not found in the strewnfields. Moreover, the tektites themselves were clearly melted at the time when they were formed; they correspond to large and delicate drops, which are difficult to reconcile with a terrestrial impact origin. "If the tektites of each strewnfield originated as large chunks fran the moon which melted during a grazing entry into the earth's atmosphere it may be possible to understand the shapes. (A chunk from the earth could not re-enter the atmosphere at a grazing angle.) 
Again it is argued that the chemistry of the tektites resembles the earth's crust far more than any meteorite. This argument is correct; it should be noted, however, that the differences from terrestrial chemistry are also highly significant. For instance, telitites contain about $1 / 100$ as much water as relatively dry terrestrial rocks. To remove such water is known, from the long experience of the glassmaking industry, to be a laborious process involving hours even when the materials are chosen for dryness and for low melt viscosity. Tektites constitute a glass more viscous than any which is ordinarily produced by melting in the glassmaking industry. It does not appear conceivable that the amount of water found in most terrestrial rocks could be eliminated by impact. In fact, most of the undoubted impact debris is very vesicular, unlike tektite glass, which is normally solid.

The chemical resemblance between tektites and the earth's crust is so close that if it finally turns out that tektites come from the moon we shall be led to think that the moon itself comes from the earth. For example, in most: samples of cosmic matter, such as the sun or the meteorites, the nickel content is about $10 \%$ that of the iron. In tektites the ratio is more like 18 , and the same is true for the earth's crust. In the latter case it is customary to explain the deficiency of nickel by saying that the nickel was leached out of the earth's mantle by the descent of metallic iron to the core of the earth. If so, then perhaps the moon lost its nickel because it once formed part of the earth's mantle. 
The tektites as a guide to the moon

On the positive side, there is reason to think that tektites came from the moon because the coesite assures us that the material of the Muong Nong tektites has not been remelted since it suffered shock. It is a glass; and hence the surface on which the impact took place was a glass, and in fact a rather peculiar glass, of a type not known on earth: water-free or nearly so, and with unexpected proportions of alkali oxides and alkaline earths.

Petrographically, the Muong Nong tektites appear to all observers to be originally clastic--i.e., fragments. Since they now form a reasonably dense glass, the logical explanation is that they are a sort of welded tuff. Welded tuff is a volcanic rock formed by the sintering, after deposition by ash flows, of volcanic ash and pumice fragments (Smith, 1960). The ash is erupted from a fissure while hot; it contains gases, especially steam, ' which gradually diffuse out of the ash particles and move upward through the hot bed of ash. The moving gas separates the particles slightly from one another, so that they can pass each other without friction. The whole mass is then fluidized, or transformed into a sort of liquid of low viscosity, which pours downward over any existing slope with a velocity which, on earth, may be up to 50 meters per second. Above the pseudo-liquid there is likely, especially on the moon, to be a pseudo-gas, consisting of small particles of ash falling through the escaping steam, and giving the mixture a density higher than most ordinary gases. On the moon, it is possible that the pseudo-gas may be the dominant means of transport. 
In any case, the tektites of the Muong Nong type appear to have been deposited by one of the above processes. Since they are chemically dissimilar to terrestrial welded tuffs, it is excessively improbable that great impacts such as those required to produce the Far Eastern or the North American strewnfields should have taken place always in the rare or nonexistent places where such tuffs are found. It is far more likely, in principle, that they should have taken place on the moon, where we should expect the low water content. '

Comparison with the Ranger photographs

It is interesting to compare the notion of ash flow tuffs as the Iunar surface material with the Ranger photographs. In the first place, we note among the photographs taken at relatively low altitude and utilized for the Ranger VII 1:100,000 map of Mare Cognitum (Fig. 1) that there is strong, evidence of lineaments trending from northeast to southwest. Among the features displaying this tendency are the Riphaeus mountains on the border of the sea; several similar ranges of steep-sided hills, for which the : name arêtes has been proposed; and a number of the much lower and flatter ridges called wrinkle ridges. The latter are generally somewhat curved; the preference for the NE-SW direction manifests itself sametimes in the center of the curves and sometimes by the breakup of the ridge into a set of parallel ridges running as mentioned.

There is a similar but weaker trend perpendicular to this one. 
At still lower eltitudes (Fig. 2), one of the aretes is visible at the lower right. Prolonging its direction, we come first to a dome, so steepsided that it casts a shadow, though the sun is $21^{\circ}$ above the horizon, then to a low black ridge, which interrupts the rays from the lunar craters Tycho and Copernicus, which traverse the Mare Cognitum.

The meaning of these last features seems to be the following:

a. They are volcanic, rather than the result of impact, because they follow the trend of the fractures in this region, as established from, e.g., the wrinkle ridges.

b. Some at least represent intermediate or acid volcanism, because the ridges have steep sides. Acid igneous rocks (1.e., those with $60 \%$ or . more of $\mathrm{SiO}_{2}$ ) form viscous magmas, which are conspicuously different in their physical properties from the basaltic magmas, such as the Hawalian lavas, with about $50 \% \mathrm{SiO}_{2}$. Some intermediate lavas (andesitic) with $55 \% \mathrm{SiO}_{2}$ may also be viscous. The viscous lavas are very likely, on earth, to give rise to ash flows (Smith, 1960), because the ash represents a smashed rock froth; and the bubbles escape only with difficulty from the viscous lavas. The basalts, on the other hand, at least on the earth, are less likely to produce ash.

c. The fact that the black ridge cuts across the ray structure is highly significant because in general the ray structure is belleved to be recent. Thus the black ridge probably is more recent than the rays in conjunction with points $\mathrm{a}$ and $\mathrm{b}$; it is evidence of recent acid or intermediate volcanism. 
The point is importent because the dating of tektites by rubidiumstrontium methods indicates that they are formed from rocks erupted, not at the presumed beginning of the history of the moon, 4.5 billions ago, but 2 billion years to 300 million ago, (Schnetzler and Pinson, 1963). If they are from the moon, they imply continuing acid volcanism on the moon, and it is thus a significant confirmation of the lunar origin of tektites that the Ranger photographs indicate the same.

A second significant feature of the Ranger photographs is the evidence that craters in the range of diameter from 50 to 200 meters are shallow, and have less steep slopes than those which are either much larger or much smaller. The result is sometimes attributed to erosion by micrometeorites; but against this explanation there are at least 3 powerful objections:

a. It does not explain the fact that the small craters are again steep-sided.

b. It requires the existence of bare rock slopes over some areas of the moon; if erosion is going to produce an accumulation of debris in scme areas, there must be other areas where debris is being formed. But there is: strong evidence from thermal studies that the Iunar highlands are covered in almost the same way as the lowlands.

c. Studies of the darkening of the moon by solar radiation, especially the protons of the solar wind, have shown that a period of 100,000 years is required to produce the observed amount of darkening (Wehner, 1964). The darkening extends only to a depth of a fraction of a millimeter; if we say $0.1 \mathrm{~mm}$, this means that if erosion by micrometeorites 
goes faster than 0.1 in 100,000 years, or I in 1 million years, the moon cannot be darkened. Hence in a few billion years (the probable age of the mocn) erosion will amount to only a few meters, which is insufficient to explain the observed softening of the outlines of large craters.

The phenomenon is easily explained by the ash-flow mechanism. Suppose that a layer of ash some 50 meters deep is deposited over the region. This will coat the insides of the craters $I$ kilometer across without seriously changing their shape. It will, on the other hand, fill up the 200 meter craters, which are only about 50 meters deep, and, of course, it will fill all the smaller craters. Once the layer is deposited, however, there will be a compaction, especially since the fragments of glass are still hot and plastic. Under the weight of overlying layers, the material may even weld into a solid mass, called on earth a "welded tuff". The compaction will be greatest where the tuff is deepest and least where it is shallow; thus. the contours of the buried terrain will re-emerge, but softened. This process is well-known in terrestrial ash flows under the name "differential compaction" (Smith, 1960).

The smaller craters will, of course, vanish for good. But after the ash flow the infall of meteoritic matter will produce new craters, and since there are many more small meteorites than large ones, we shall expect the great majority of the post-ash-flow craters to be small; there vill be (and are) a few larger ones.

Before concluding our discussion of the Ranger photographs, it is of. interest to compare them with the topography of the Valley of Ten Thousand 
Smokes, in Alaska, which was the site of a violent eruption of volcanic ash in 19i2. Much of this ash is in a semt-welded condition, and this area is important as an example of the terrain produced by ash flows.

Examination of Figs. 3 and 4, transmitted by Ranger IX as it approached the crater Alphonsus, reveals several striking characteristics of the lunar surface even more clearly than did the earlier Ranger pictures. First, the generally subulued, rolling nature of the crater floor is apparent. Second, we note the gradational, smooth contact between the crater floor and walls. Third, and most surprising, is the smoothness of the rim and adjacent highland areas and of the central peak of Alphonsus.

All of these characteristics have counterparts in the Valley of Ten Thousand Smokes. In Figs. 5 and 6, we see the general smoothness and flatness of the valley floor, interrupted chiefly by post-eruption guilying. In addition, we see the gradation from valley floor to the surrounding hills, and finally the smoothness of the hills themselves (again, roughened chiefly by recent erosion), caused by the blanketing effect of volcanic ash.

These similarities do not, of course, prove without doubt that regions such as Alphonsus are underlain by volcanic tuff, but they appear completely consistent with such a possibility.

Conclusions about the moon

This theory gives a reasonably good explanation both of the Ranger photographs and of the Muong Nong tektites. If it is correct, however, we . must accept certain further conclusions about the moon's surface. 
a. The ash flows which produce tektites contain glass plus quartz crystals. They do not, for example, contain crystals of feldspar - which is surprising. Dr. I. S. Walter, at Goddard Space Flight Center, has discussed the problem of differentiation under expected Iunar conditions -especially very low partial pressure of $\mathrm{H}_{2} \mathrm{O}$-- and believes he has a solution.

b. Turning to the famous question of the origin of the moon, if the tektites are from the moon, it is hard to doubt that the moon itself is derived from the earth, probably after the formation of the core of the earth. The argument was noted above; it rests on the general chemical similarity; on the particular question of nickel abundance; and on the similarity in density between the earth's mantle and the moon. This latter point must not be too strongly pressed, however, since at least same calculations of the internal density of the earth have started from this assumption, raising the possibility of a circular argument.

Wise (1963) has suggested that it was the formation of the core which led to the splitting off of the moon. This explanation requires the further assumption that at some later time in the history of the earth-moon system about $3 / 4$ of the total angular momentum escaped, perhaps through some mechanism of magnetic interaction.

It will be seen that these speculations, though plausible, cannot claim to be more until we are assured that the surface of the moon is genuinely like tektites in its chemical composition. The importance of the 
REFERENCES

Chao, E. C. T., I. Adler, E. J. Dwornik and J. Littler, Science, 135, 97 , 2962.

Chapman, D. R., Geochim. et Cosmochim. Acta, 28, 6, 841-880, 1964.

Charters, A. C., High speed impact, Scientific American, 203, 128, 1960.

Cohen, A. J., Asteroid- or comet-impact hypothesis of tektite origin: the moldavite strewn fields, in Tektites, ed. by J. A. O'Keefe, University of Chicago Press, Chicago, 1963.

Gault, D. E., E.'D. Heitowit and H. J. Moore, Some observations of hypervelocity impacts with porous media, pp. 151-209 in The Lunar Surface Layer, ed. by J. W. Salisbury and P. E. Glaser, Academic Press, New York, 2964.

Kopal, z., Preface, in The Lunar Surface Layer, ed. by J. W. Salisbury and, P. E. Glaser, Academic Press, New York, 1964.

Mason, B., Meteorites, John Wiley and Sons, New York, 1962.

Nininger, H. H., Sky and Telescope, 2 (4 and 5), 1943.

Schnetzler, C. C., and W. H. Pinson, Jr., The chemical composition of tektites, in Tektites, ed. by J. A. O'Keefe, University of Chicago Press, Chicago, 1963.

Shute, B. E., Astron. J., 67, 283, 1962.

Smith, R. I., Bull. Geol. Soc. America, II, 795-842, 1960.

Spencer, L. J., Nature, 132́, 571, 1933. 
Suess, F. E., Jahr. GeoI. Re1chanst. (Bundesanst.), Wien, 50, 193-382, . 1900.

Urey, H. C., Nature, 179, 556-557, 1957.

Verbeek, R. D. M., Proc. K. Akad. Wet. Amsterdam, 2, 421:

Viste, E., and E. Anders, J. Geophys. Res., 67, 2913, 1962.

Walter, L. S., Science, 147, 36631, 1029-1032, 1965.

Wehner, G. K., Sputtering effects on the Iunar surface, in The Lunar Surface Layer, ed. by J. W. Salisbury and P. E. Glaser, Academic Press, New York, 2964.

Whipple, F. L., and R. F. Hughes, Jour. Atmospheric and Terrestrial Physics, Special Supplement, v. 2, pp. 149-156, 1955.

Wise, D. U., J. Geophys. Res., 68, 1547-1554, 1963. 
Fig. I Photograph taken by Ranger VII before impact on $3 I$ July 1964. North is at top. Area shown is about 113 miles on a side. Smallest visible craters are about 1000 feet in diameter.

Fig. 2 Photograph taken by kanger VII before impact on $31 \mathrm{July} 1964$. North is at top. Area shown is about 48 miles on a side. Smallest visible craters are about 500 feet in diameter.

Fig. 3 Photograph taken by Ranger IX before impact on 24 March 1965. North is at top. Area shown is east rim of Alphonsus.

Fig. 4 Photograph taken by Ranger IX before impact on 24 March 1965. North is at top. Area shown is center of Alphonsus; central peak at bottom center.

Fig. 5 Photograph taken by H. Coulter of the U. S. Geological Survey in the Valley of Ten Thousand Smokes, Alaska. Valley floor, in foreground, is volcanic ash.

Fig. 6 Aerial photograph; courtesy of the Army Map Service, of the Valley of Ten Thousand Smokes, Alaska. 